\title{
Storytelling in data visualization: information bias
}

\author{
Jaqueline Vasconcelos Braga, Tiago Barros Pontes e Silva
}

Datavis, visual graphics, data storytelling, perception bias, information visualization

\begin{abstract}
Storytelling is shown as an effective approach to humanize information perception. However, its potential to build a biased view of the information contents is often neglected. Moreover, narrative understanding and emotion may interfere with data visualization comprehension. In this research, we evaluated how users perceived the information in two different configurations: One with a report with graphs and narrative side notes texts, and the second with a redesigned fully annotated content. The test compared the two groups in both qualitative and quantitative methods. The quantitative results were obtained by a survey and statistically analyzed with a T-Test. This indicated that the condescending storytelling approach augmented the perception of the effect signaled by the presented narrative. Also, the qualitative results collected afterward by interview and focus group have shown that, as the readers of narrative models perceived a higher intensity of the effect, they have also expected an even higher result from the selected data. The final analysis of the experiment helped to indicate that ordering, highlights, and semantics have a strong role in how the narrative influences the perception of the reader.
\end{abstract}

\section{Introduction}

The use of data is frequently presented as a tool for pointing facts or as an indicator of truth (Campbell, 2018; Dahlstrom, 2014). Often, its use aims to confirm the validity of a particular opinion (Dove \& Jones, 2012; Fekete et al., 2008). Also, data presentation induces different inferential models despite the main content (Campbell, 2018). Nowadays, in a context where more data is always available, finding models to simplify and optimize information retrieval is paramount. Data visualization resources play a significant role in the process of information acquisition, as they provide a much shorter pathway for the content reading cognitive process. In terms of complexity, either reading a graphic or reading a text requires the same interpretative models, despite their divergent encodings. The biological cognitive apparatus, however, works differently for images: They are perceived faster but the brain requires continuous visual scans to fully understand the image's theoretical, ontological, semantical, and semiotic contexts for its comprehension (Bae et al., 2019). The brain requires memory to understand the image that is being seen and image cognition processes are somehow closer to textual comprehension. In both written or spoken contexts, the system of 
codes for the text comprehension relies on the memory of the reader/ listener. Therefore, memory processing is biologically related to affective processing, which makes the memory more susceptible to emotions (Bae et al., 2019).

This character of hastening the cognitive process is one of the main reasons to motivate the use of data visualization. Graphics can aggregate a large amount of data into one single resource. The process of information retrieval from data visualization allowed us to achieve inferential knowledge from larger datasets with the bonus of making it also accessible to larger and more diverse audiences. In this context simpler and more memorable approaches to data became more relevant such as the data storytelling approach. Storytelling for data can help readers to understand high-complexity sciencebased subjects (Dahlstrom, 2014), and Institutions such as UNECE - United Nations Economic Commission for Europe - among others, recommended the use of data storytelling as the main approach to publishing economic data (Unece, 2009, 2011; United Nations, 2014). What makes this approach powerful is that these narratives and rhetorical resources have benefited from both the memory and the affection processing of the individuals. A neglected possible side effect of using storytelling as a data visualization approach is that often our emotions play a wider role in the cognition of the images - as its dynamics go back and forth from memory to affection and visual recognition, and that could amplify the information bias. Therefore, this study aims to investigate how users perceive the information in two different approaches: With and without narrative side notes, evaluating its impacts on the perceived storytelling.

\section{Literature review}

Sarah Campbell (2018), when analyzing data visualizations, identified traces of Aristotle's rhetoric based on the concept of "Pathos" as the main tool for persuasion on graphics; showing that the narrative vehicle also performed a strong influence on the persuasive result of a much logical product. Kennedy and Hill's (2018) findings also point out that the engagement with data visualizations "evoke emotional responses that nuance the proposal that numbers alone are central to the logic of datafication" (Kennedy \& Hill, 2018). Hullman and Diakopoulos (2011) described as "surprising" the effects of subtle rhetorical manipulation on data visualization. Their findings also indicate that both individual and social codes perform significant variations on the resulting perceived content (Hullman et al., 2011; Hullman \& Diakopoulos, 2011). Another study, performed by Pandey et al. (2014) investigated the attitude of the readers of information graphics accordingly to their beliefs by presenting a specific persuasive message and measuring the changes in the attitude towards a subject. The results indicated that participants with a more neutral or weakly polarized view toward the 
subjects were more likely to be influenced by the persuasive message (Pandey et al., 2014). The main effects indicated by the authors in sustaining participant's beliefs against the persuasive content were: (a) Skepticism - with the data/source and the logic provided - , anchoring perception to core beliefs; (b) the complexity of the presented message; (c) and if the participant was previously persuaded accordingly to the adopted message. The results indicated that the least polarized individuals could be more susceptible to persuasive narratives, therefore the individualization of the data perception should consider beliefs, emotions, knowledge, and social codes as part of its narrative, and consequently how its meaning is defined.

Maggino and Trapani (2009) indicate that the three pillars of presenting statistics are contents, appeal, and persuasion. The corresponding disciplines composing its theory of presentation for each aspect then would be ethics, aesthetics, and rhetoric. For the authors, "statistical communication takes for granted that all stages of data production have been accomplished by respecting all best practice codes" (Maggino \& Trapani, 2009, p. 10). Bresciani and Eppler (2015), however, present a more skeptical view over the subject as they explore pathways to identify what they call, potential "pitfalls" for information visualization. Their work presents a solid theoretical matrix for evaluating the presence of drawbacks on both the encoding side - designer-induced - and decoding side - userinduced - of the data visualization product. By providing analysis on cognitive, emotional, and social sides of visualizations, the authors have developed a comprehensive and extensive classification matrix of pitfalls of data visualization resources that could help professionals as well as non-experts in visualization production (Bresciani \& Eppler, 2015). Connecting these works with the narrative perception of the data visualization can support a more complex reflection on visual graphics, adhering both form and contents to a deeper analysis.

The concept of narrative on data visualization pervades its visual structure and its mechanics since elaboration. Whilst the editorial narrative piece reflects the profile of the individuals who selected the data, the visual representation is a more subtle tool for the same objective. The features of the data design space are closely related to the media that they are anchored to. These models should be constantly updated according to new media and resources technological evolution. Furthermore, the Segel and Heer's (2010) design space framework suggests design strategies for narrative visualization not solely based on how the user explores the data but also on how those visual representations are placed into the rhetorical composition. They are: (a) the martini glass; (b) the interactive slideshow; and (c) the drill-down story. Each structure combines a spectrum of author-driven and reader-driven experiences through the data visualization, composing the narrative between the interaction of both experiences (Segel \& Heer, 2010). The narrative author-driven approach creates a more interesting data visualization product that 
leads the reader directly towards an insight offering a balanced experience between exploratory and expositive content. Unbalanced interaction levels or excessive expositive contents may leave too little room for the reader to understand or to explore the content, two conditions that could impact negatively the reading process (Figueiras, 2014). Considering that emotional stimuli affect the perception of the narrative (Harrison et al., 2013; Kennedy et al., 2016) and validity and trust are susceptible to the individual perception and openness to the subject (Bresciani \& Eppler, 2015; Harrison et al., 2012; Kennedy et al., 2016), we decided to investigate the potential of bias added to a visual resource by the use of a narrative approach on data visualization.

\section{Designing the experiment}

The experiment consisted of applying the same textual content and equivalent graphs over two different approaches in two groups: (a) Using the original report for the control group, with pictures and texts presented separately; (b) a redesign layout with the same model of charts and combined texts. The research design is presented in Fig. 1. The entire instrument was written in Brazilian

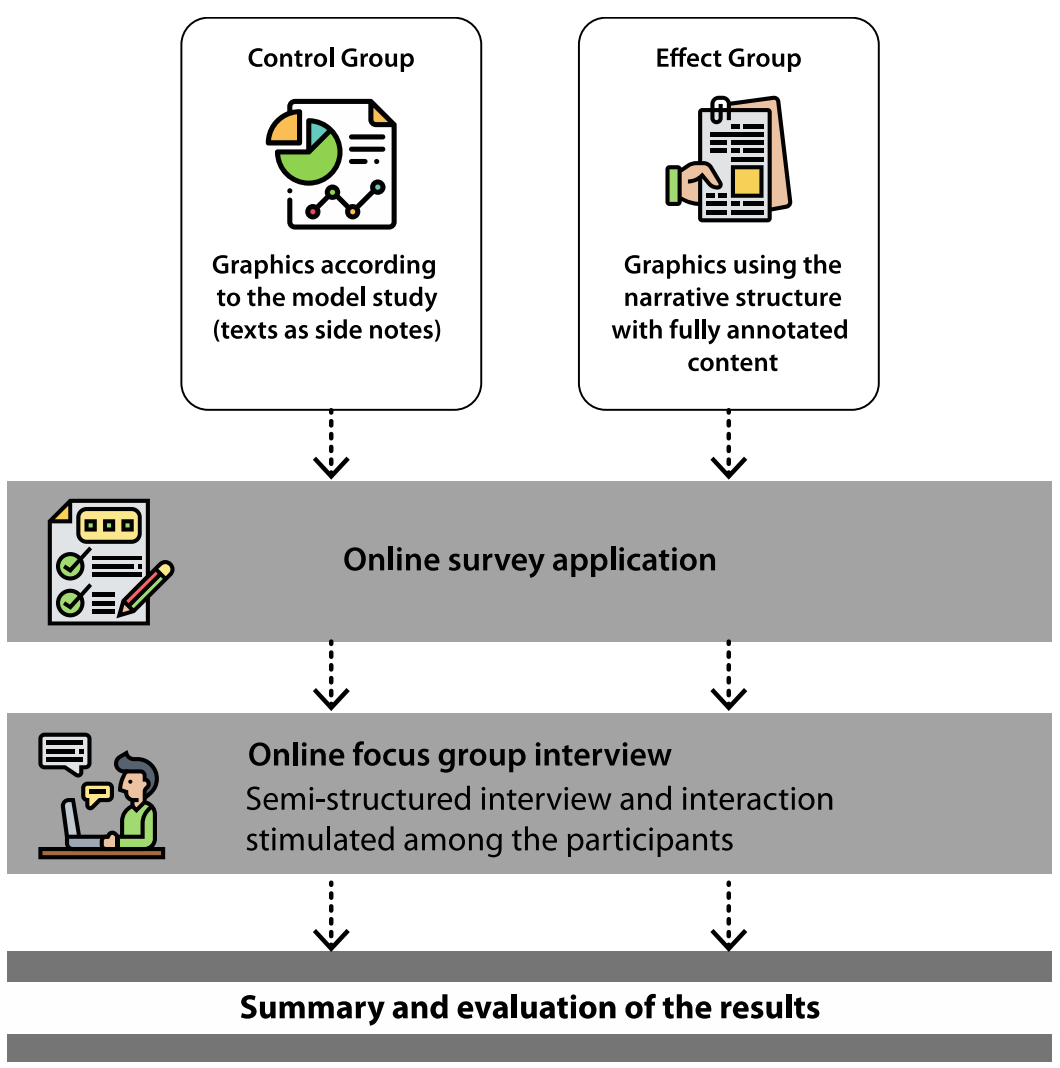

Figure 1 Research design with Control Group ( $n=14)$ and Effect Group $(n=18)$, both evaluated with questionnaires and focus groups interviews. Source: image created by the authors. 
Portuguese. The content used for the instrument was selected from a study published a few years before this research, the racial and gender gap on the Brazilian labor force, originally named "Segregação Ocupacional por Gênero e Cor em Goiás - 2011 a 2013", developed with Brazilian Institute of Geography and Statistics (IBGE) Continuous National Household Sampled Survey (PNAD) datasets. The study, however, is signed by Mauro Borges Institute of Statistics and Socioeconomic Studies researchers, published in 2015. For this experiment, a set of 13 questions were presented to the participants with mixed parts of the report. The content was presented as it was originally published with a side-text for the control group (Fig. 2) and as a narrative annotated Infographic for the effect group (Fig. 3). Both groups were evaluated on quantitative and qualitative methods. The participants were required to answer the questions reasoning their understanding of the content and then joined a focal group to underline how they perceived the presented information.

Emotional perception and general comprehension of the visual contents of the graphics have been investigated by the survey. The general comprehension questions and the final model of the graphics presented to the effect group were designed according to the Visual Literacy Assessment Test - VLAT (Lee et al., 2017) to ensure that both presented models would have a similar difficulty rate. At this stage, design decisions were considered so that the new layout would have internal consistency, as the original report consisted only of pictures isolated from the text. This also caused the modification of some related graphic elements, as the bars thickness and coloring pattern, which may also have influenced the participants, being considered a research limit. Nevertheless, we did not expect to find out discrepancies between the groups reading of the numerical content itself. Personal perception questions would indirectly address participants' age, race, and gender to recognize if some participants would self-identify as belonging to a more susceptible group according to the main subject of the graphic women, and people of color. The group interview was shaped to focus on the expression of trust in the content and to stimulate interaction for discussing the contents of the graphics. Finally, the interview identified the strategies of the storytelling and the participant's perception of the narrative. The interview structure had neutral questions, asked in the same order to both groups and with minimal intervention while the participants discussed the contents among themselves. For this study, the most relevant questions were those related to the perception and the emotion caused by the graphics. 


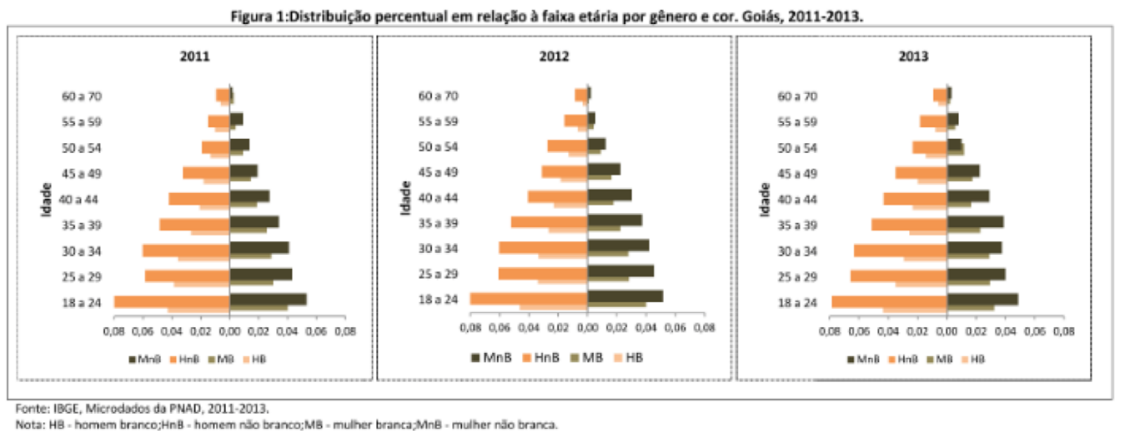

Figura 2 - Distribuição percentual por faixa de escolaridade, em relação a gênero e cor. Goiás, 2011-2013.
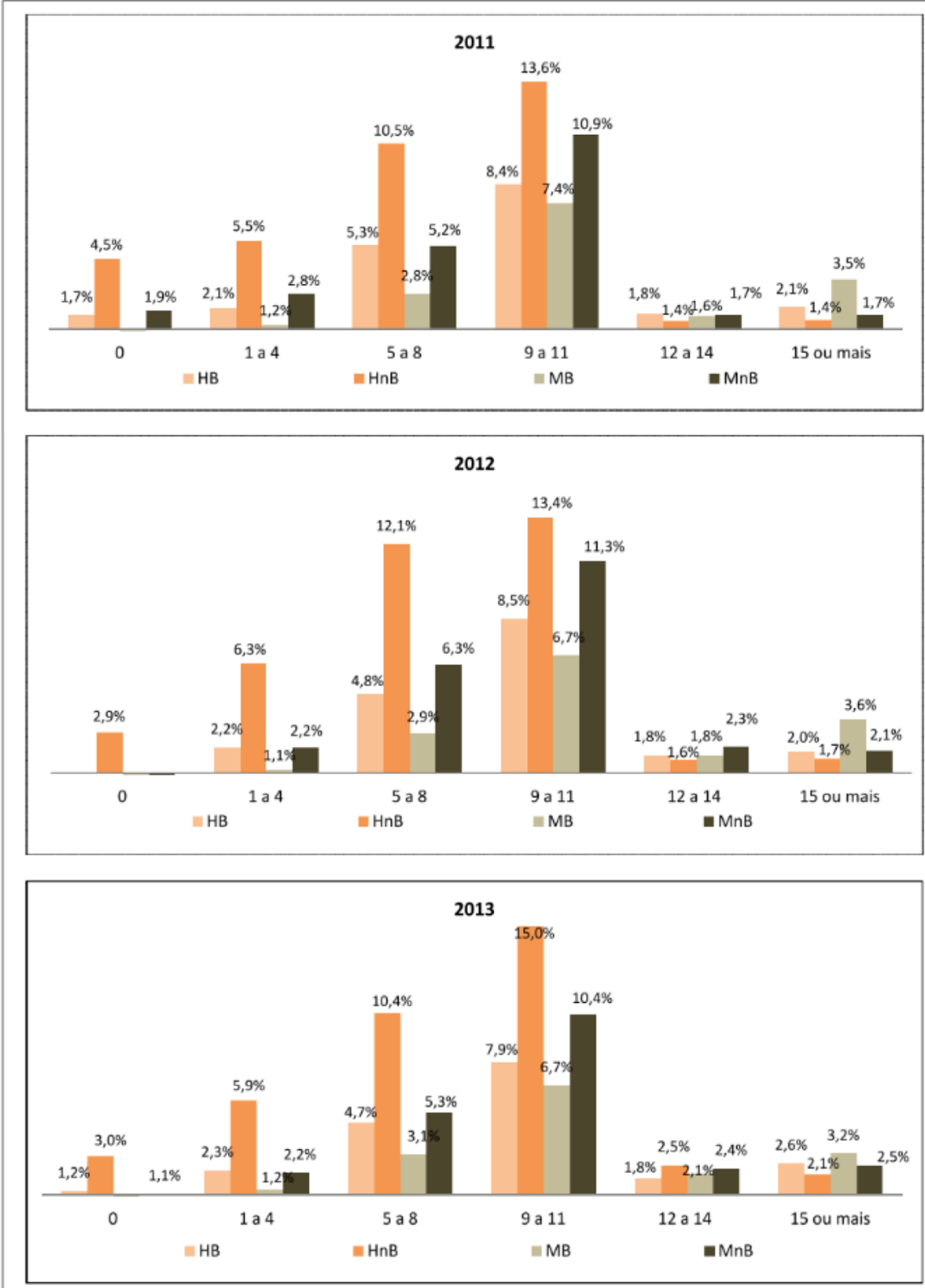

Figure 2 Example of how the graphs were presented in the instrument layout, which also contained the side text and the 13 questions for the Control Group. Source: Mauro Borges Institute of Statistics and Socioeconomic Studies, 2015. 
A população está começando a trabalhar mais tarde...

A pirâmide étária mostra uma pequena alteração na idade do trabalhador entre 2011 e 2013: a participação dos mais jovens caiu 1,64\% enquanto os trabalhadores com idade entre 45 a 49 tiveram um aumento de 1,08 p.p. no período.

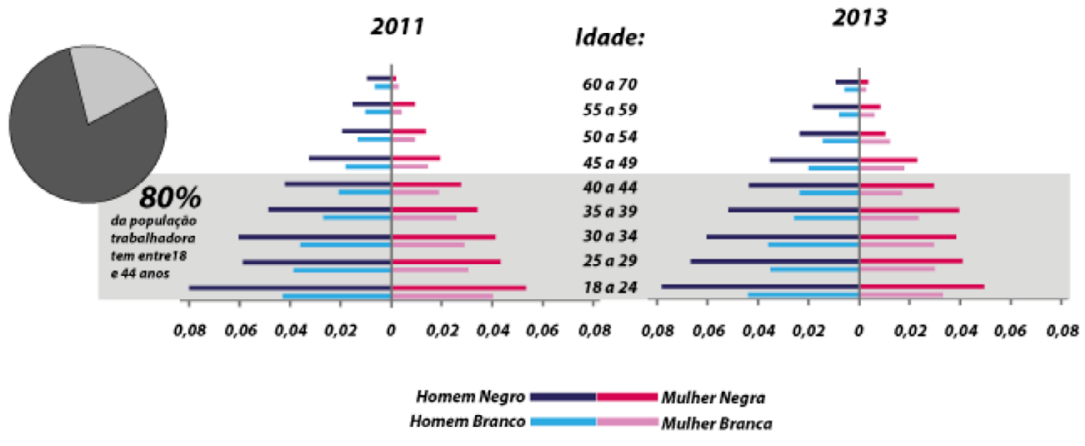

\section{As maiores mudanças são quanto à qualificação}

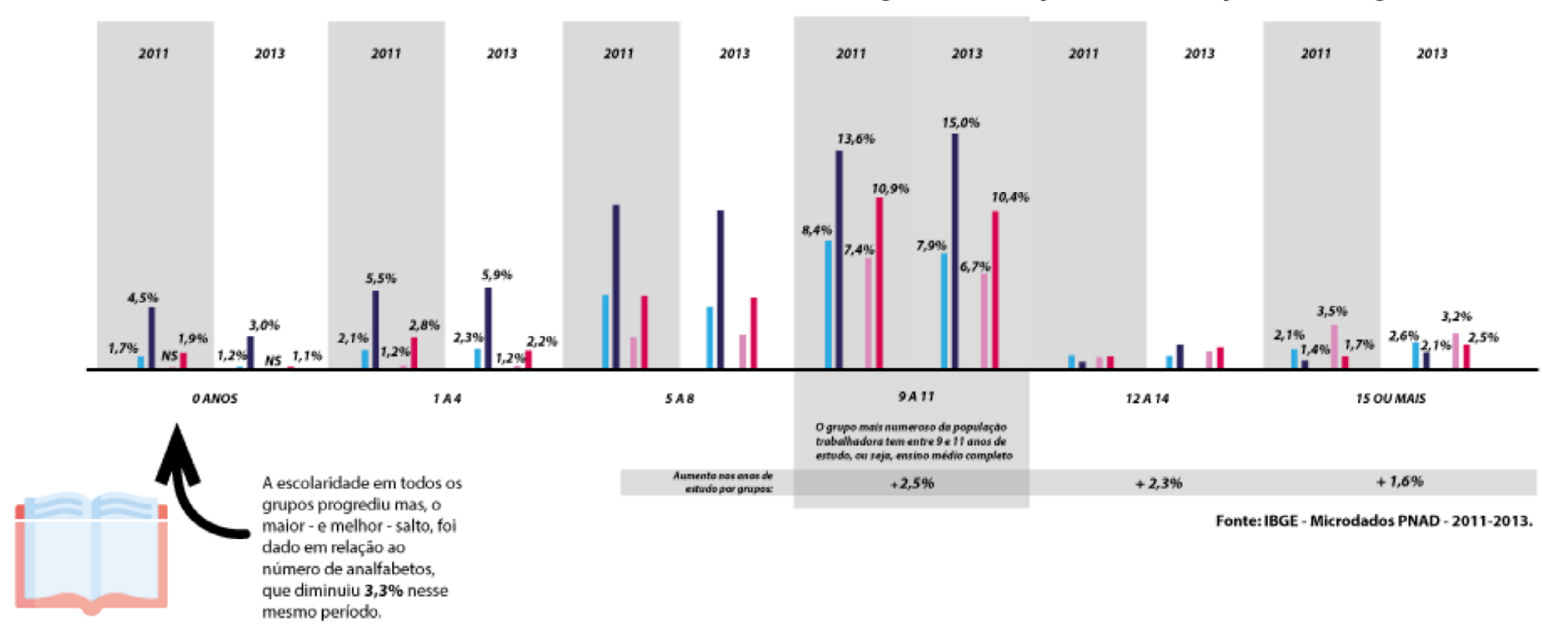

Figure 3 Example of the narrative annotated Infographic presented with the 13 questions in the instrument layout for the Effect Group. The graphs were redesign and mixed with the side-text. It was also presented with the 13 questions. Source: image created by the authors.

Two groups of university students voluntarily agree to participate in the online survey and focal group interview. The control group held 14 participants and the effect group 18 participants in two synchronic online meetings. The first group chose the Teams platform and the second Zoom Meetings tool for its interview. No participant was discharged from the voluntary participation and the only requirement was to be in beginning of their own courses. The questions over the visual graphic literacy were used to compare both groups' understanding of the values and basic contents were presented on the images solely. No strong differences in literacy were found between groups which provided us better conditions to investigate the perceived effects of the data storytelling.

Self-identifying characteristics indicated that $56.2 \%$ of the participants were part of a populational majority group, 59.3\% had not suffered racial injuries, and $87.5 \%$ believed that gender equality isn't 
achieved yet. This last aspect must be seen as potentially biased by the bandwagon heuristics - conformity bias - which probably made this effect larger. The mode of the time needed to answer the survey was 21.5 minutes, and the interview length was 38 minutes for the control group and 36 minutes for the effect group. The 13 questions presented to the participants were of different types: Multiple choice, single choice, ordering and agreement scale. The subjective perception of data was dealt with in three specific questions (presented here as number 1, 2, and 3), all of them in the same mechanics: a scale conceptually anchored at the extremes from zero to one hundred, with a step increase of one point, going from zero - no effect - to one hundred - highest perceived effect (Fig. 4). These answers were statistically evaluated in a Student's T-Test to identify if the mean difference for both groups would indicate the presence of the effect.

Em suma, os dados apresentados pelo gráfico parecem ser: *

Arraste o indicador do centro da barra em direção ao que você acredita ser correto quanto ao realidade das informações reportadas no gráfico.

Nada realistas $\square$ Completamente realistas

Figure 4 Example of the scale mechanics adopted for questions 1, 2, and 3, where the subjective perception of the data was collected. Source: image created by the authors.

\section{Results}

At question ' 1 - Perception of the intensity of the effect shown by the graphic', where zero means "there is no perceivable effect" and one hundred means a "clearly perceivable effect", the effect group that received the storytelling-based graphic had a response that indicated a stronger connection between the graphic results and the effect presented, with a difference of the means value varying on $t 4.792$ $(p<0.0001)$.

At question ' 2 - inquiring on how trustful where the information presented by the graphic', with zero meaning "unrealistic graphic content" and one hundred meaning "the graphic presents a trustworthy content", the effect group also had a more skewed distribution signaling less doubt on the graphics content, with a significance of $p<0.0001$ for $t 4.377$ difference of the mean values attributed to their perception.

At the final question on perception, ' 3 - emotional response to the content exposed by the graphic', where zero held the meaning of "Indifferent" - the absence of positive or negative emotions, and one hundred was valued as "Alarmed" - attention drawn caused by a positive or negative impulse, the effect group expressed a more 
intense emotional reaction to the contents, with attributed values means showing a variation $t 4.495, p<0.0001$ significance index. The frequencies for these three questions are shown in Fig. 5.

The interview was carried out immediately after the survey application, where the participants indicated those differences of perception about the information acquisition. The control group which had received the graphics isolated from the texts - expressed a diluted perception between the factors indicated as correlational. The effect group, on the other hand, consistently reported a lack

1 How do you perceive the intensity of the relation between workers' race and gender and wages by groups presented by the graphic?
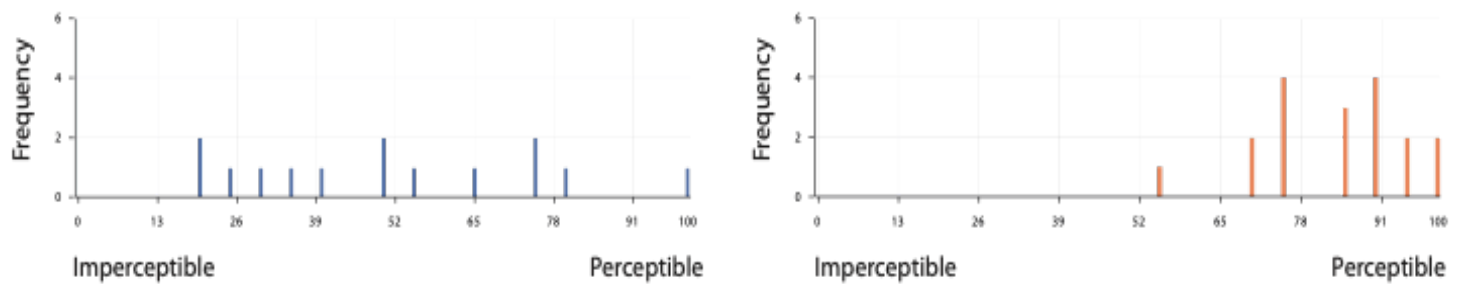

2 How much do you believe that the information presented by the graphics is trustful?
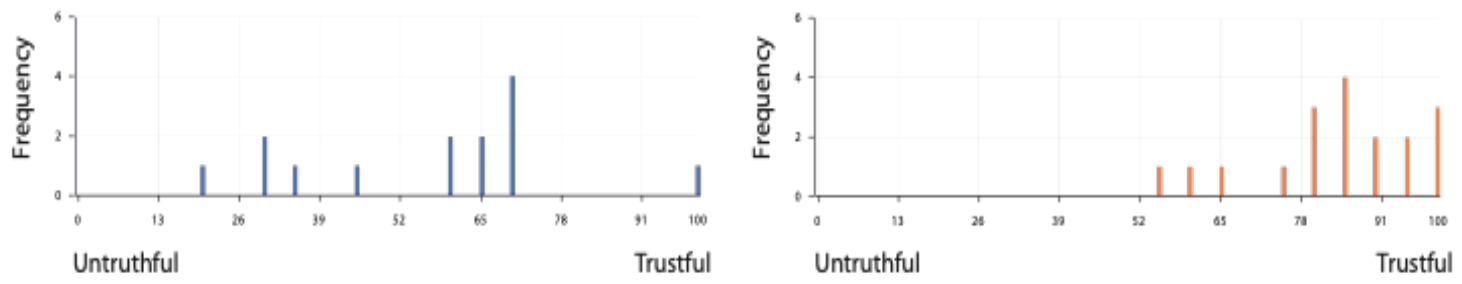

\section{How do you feel about the information presented by the graphics?}
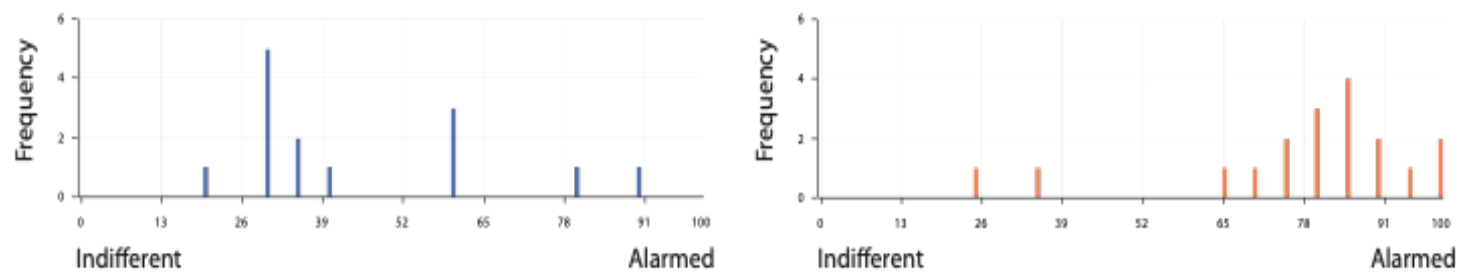

Figure 5 Comparison between Control Group (left) and Effect Group (right) on the answers to the questions " 1 - How do you perceive the intensity of the effect presented by the graphic? Consider zero as 'there is no perceivable effect' and one hundred as 'clearly perceivable effect", " 2 - On a scale from zero to one hundred, how much do you believe that the information presented by the graphics is trustful? Consider zero as 'completely untruthful' and one hundred as 'completely trustful'" and, " 3 - In a scale from zero to one hundred, how do you feel about the information presented by the graphics? Consider that zero means 'indifferent - doesn't cause any positive or negative feelings' and, one hundred means 'Alarmed - positive or negative feelings are instigated by the content of the graphic"' respectively. Source: image created by the authors. 
of intensity of the reported data exposed, as if its elaboration were framed considering a more cautious presentation, attenuating the final effects of the content information of the graphics.

Both groups have identified the database's source but neglected the graphics' elaborators as belonging to a different affiliation. The participants' trust in the data source is reflected by the identification of the structures of the graphics they read. The effect group has considered the ordering of the sentences, the highlights that are taken from the graphics, and the used vocabulary as relevant elements to the narrative composition of the graphics. However, they could not recognize how those elements were shaping their perception of the results. These specific topics, when connected to the differences found in the perception of the readers, corroborate that the data storytelling is a rhetoric tool for persuasion that can become a source of bias of the information. Therefore, we understand that the features highlighted by the participants about the narrative structure should be the first ones to be analyzed when investigating models to recognize and reduce the effects of this potential bias on datavis.

\section{Discussion}

Both visual resources shared the same difficulty index according to Lee et al.'s (2017) visual literacy assessment test (composed by the same style's bar charts). We consider that the presence of the annotated sentences has conducted the interpretation's flow in the narrative model. This result was expected given that the theoretical argumentation supports the use of this model for its potential of simplification (Hullman and Diakopoulos, 2011). As we believe that the ethics on the data elaboration and journalism may be achievable ( Lee et al., 2015) and (Maggino and Trapani, 2009), the presence of the storytelling is a guideline that affects the perception of the data by the readers of the content. In our case, we believe that rhetoric had a stronger effect conducting or altering the interpretation of the reader. The fact that we used the exact same text content to support the visual hints suggested by the graphics - only changing details at the sentences for a better fitting along with the graphics annotations created the effect of the narrative approach. Nevertheless, the design changes have become intervening variables in the study, limiting its inference potential. For the next evaluations, a third group can be investigated for comparison, in which an identical version of the infographic can be used, just eliminating the auxiliary texts, applied after the presentation of the graphics, as in the original report. This should allow a more accurate assessment of some graphic elements changing, such as bar thickness and color patterns.

The presence of the identifiable author, the Aristotle's Pathos remarked by Sarah Campbell (2018), was found along with our results. The participants firmly considered that the identification of the source 
is a key point for the trustworthy perception of the data visualization presented. Concerning the data design space, both products used in this study were static, with a low interaction level. As the effect group may have experienced a more engaging experience, given the visual structure of the graphic they received, the participant recruitment strategy, consisting of maintaining the participants for a subsequent second activity, possibly held the participation engagement until the end of the experiment.

The evaluation of the results indicated that the narrative articulation has affected the readers' final perception of the data visualization content. We proceeded to analyze the features of this narrative incursion. The narrative composition components listed by participants are: (a) the conscious ordering of the subjects in a logical structure; (b) the highlighted contents picked out from the text and doubled by the graphic labels; and (c) the articulation of more or less formal words selected to express the message, with Bresciani and Eppler (2015) systematic approach. The storytelling reflects a structure suggested by the development of the visual content. It can be classified as part of the encoding - designer-induced - on Bresciani and Eppler charts. Therefore, the three elements were connected to this specific category.

The first one is the (a) ordering tool. It creates a logical pathway connecting one content to another in a scale of interests and conducts the reader through the acquisition of the inference defined by the developer. It corresponds to the cognitive class of pitfalls. Its construction may be anchored on different rhetorical strategies, but the perception that a visual inference could be retrieved solely by following one guided route, and not being perceivable on other exploratory readings of the data visualization, shows how that ordering may be creating a bias on the narrative structure of data. The second one is the (b) highlights. It is a selection of a specific content to attend to a particular need, something that could rely on the readers' expectations that can be closely related to the emotional class of visualization pitfalls. These highlight techniques could wrongly be related to cognitive characters. However, its strategy consists not in altering the thinking but in shaping the thinking structure, as an emotional priming. The last point of the storytelling that was recognized by the participants was the (c) semantical choice. The choice of subjects, terms and the adopted vocabulary to express the message changes the way the message is perceived. This communication interference is the main character of the social class of pitfalls described by Bresciani and Eppler (2015). Although these elements may seem simple to identify, the analysis of the applied data visualization rhetoric storytelling is a complex process. The beneficial results of evaluating these adopted storytelling decisions during the elaboration of the data visualization, however, may strengthen the readers' perception of a trustful resource. And that is what the ideal data visualization should look like. 


\section{Final words and further works}

This research investigated how users perceived the information in two different approaches: One just with narrative side notes and the other with fully annotated content. The goal was to evaluate how the rhetorical elements of the narrative impact the participants' perceptions. The results indicated that the condescending storytelling approach augmented the perception of the effect signaled by the presented narrative. Also, the qualitative results collected afterward evidenced that the readers have also expected an even higher result from the selected data. The study also showed that ordering, highlights, and semantics have a strong role in how the narrative influences the perception of the reader. Therefore, we understand that these features should be the first ones to be analyzed when investigating models to recognize and reduce the effects of this potential bias on datavis.

The results have indicated that even if data literacy materials for educational purposes being scarce, the main source of subjective interference (and potentially a bias) could be retrieved in the unprecise recognition of the narrative drawn. Our efforts then have been directed to the discovery of methods to enrich the reader perception and to offer information designers and data journalists tools to help identify and diminish the storytelling bias on data visualization. We believe that no data literacy could be truly achieved despite the comprehension that narratives and storytelling methods could be a strong source of bias. Also, this bias, as it reinforces emotional outputs, may lead the reader to become more susceptible to stand defending misinformation as true and spread this unreal perception in the same structures highlighted by Wardle and Derakhshan (2017) and Peck, Ayuso and El-Etr (2019), in which a higher emotional connection could improve the believing and the attachment to the presented information.

The study intended to add a grain of salt to a bigger discussion, and to provide an initial tool for the measurement of the impacts of the storytelling in the perception of the visual information. We are aware that other tests need to be done to recognize more rhetoric structures patterns on data visualization. Also, there is a need for a deeper evaluation of the psychological impacts of these choices on the image cognition process. We believe that communication sciences, social sciences, and digital humanities can be benefited from this. Subsequent studies on this subject will be held, especially on information management education and visual literacy. We believe that it could improve information security policies, providing frameworks to advance the data visualization development. Moreover, it could stimulate the readers to better recognize the information that is presented to them. We intend to continue the exploration of data visualization narratives and how the readers' perceptions may create a source of bias also considering the incorporation of machine learning protocols and artificial intelligence tools to improve data analytics and visualization platforms. 


\section{References}

Bae, J., Falkman, G., Helldin, T., \& Riveiro, M. (2019). Visual Data Analysis. In A. Said \& V. Torra (Eds.), Data Science in Practice (1st ed., pp. 133-155). Springer International Publishing. https://doi.org/10.1007/978-3-319-97556-6

Bresciani, S., \& Eppler, M. J. (2015). The pitfalls of visual representations: A review and classification of common errors made while designing and interpreting visualizations. SAGE Open, 5(4). https://doi. org/10.1177/2158244015611451

Campbell, S. (2018). The Rhetoric of Pathos in Visualization. Northeastern University.

Dahlstrom, M. F. (2014). Using narratives and storytelling to communicate science with nonexpert audiences. 111. https://doi.org/10.1073/pnas.1320645111

Dove, G., \& Jones, S. (2012). Narrative Visualization: Sharing Insights into Complex Data. Paper presented at the Interfaces and Human Computer Interaction. http://openaccess.city.ac.uk/1134/http://openaccess.city.ac.uk/

Fekete, J. D., Van Wijk, J. J., Stasko, J. T., \& North, C. (2008). The value of information visualization. Lecture Notes in Computer Science (Including Subseries Lecture Notes in Artificial Intelligence and Lecture Notes in Bioinformatics), 4950 LNCS, 1-18. https://doi. org/10.1007/978-3-540-70956-5_1

Figueiras, A. (2014). Narrative visualization: A case study of how to incorporate narrative elements in existing visualizations. Proceedings of the International Conference on Information Visualisation, 46-52. https://doi.org/10.1109/ IV.2014.79

Harrison, L., Chang, R., \& Lu, A. (2012). Exploring the impact of emotion on visual judgement. IEEE Conference on Visual Analytics Science and Technology 2012, VAST 2012 - Proceedings, c, 227-228. https://doi.org/10.1109/ VAST.2012.6400540

Harrison, L., Skau, D., Franconeri, S., Lu, A., \& Chang, R. (2013). Influencing visual judgment through affective priming. Conference on Human Factors in Computing Systems - Proceedings, 2949-2958. https://doi. org/10.1145/2470654.2481410

Hullman, J., Adar, E., \& Shah, P. (2011). The impact of social information on visual judgments. Conference on Human Factors in Computing Systems Proceedings, May 2014, 1461-1470. https://doi.org/10.1145/1978942.1979157

Hullman, J., \& Diakopoulos, N. (2011). Visualization rhetoric: Framing effects in narrative visualization. In IEEE Transactions on Visualization and Computer Graphics (Vol. 17, Issue 12). https://doi.org/10.1109/TVCG.2011.255

Kennedy, H., \& Hill, R. L. (2018). The Feeling of Numbers: Emotions in Everyday Engagements with Data and Their Visualisation. Sociology, 52(4). https://doi. org/10.1177/0038038516674675

Kennedy, Hill, \& RL. (2016). The Feeling of Numbers: emotions in everyday engagements with data and their visualisation. https://doi. org/10.1177/0038038516674675

Lee, S., Kim, S. H., \& Kwon, B. C. (2017). VLAT: Development of a Visualization Literacy Assessment Test. IEEE Transactions on Visualization and Computer Graphics, 23(1), 551-560. https://doi.org/10.1109/TVCG.2016.2598920 
Maggino, F., \& Trapani, M. (2009). Presenting and communicating statistics: principles, components, and their quality assessment. A proposal 12. CONFERENCE OF EUROPEAN STATISTICIANS - UNECE Work Session on Communication and Dissemination of Statistics, 10. https://ec.europa.eu/ eurostat/documents/1001617/4398464/POSTER-6A-PRESENTING-ANDCOMMUNICATING-STATISTICS-MAGGIN.pdf

Pandey, A. V., Manivannan, A., Nov, O., Satterthwaite, M., \& Bertini, E. (2014). The persuasive power of data visualization. IEEE Transactions on Visualization and Computer Graphics, 20(12), 2211-2220. https://doi. org/10.1109/TVCG.2014.2346419

Peck, E. M., Ayuso, S. E., El-Etr, O. (2019). Data is personal: Attitudes and perceptions of data visualization in rural pennsylvania. Proceedings of the 2019 CHI Conference on Human Factors in Computing Systems.

Segel, E., \& Heer, J. (2010). Narrative visualization: Telling stories with data. IEEE Transactions on Visualization and Computer Graphics, 16(6), 1139-1148. https://doi.org/10.1109/TVCG.2010.179

Unece. (2009). Making data meaningful - a guide to writing stories about numbers. New York, 21. https://www.unece.org/fileadmin/DAM/stats/ documents/writing/MDM_Part1_English.pdf

Unece. (2011). Making Data Meaningful: Part 3 - A Guide to Communicating with the Media. 55. https://www.unece.org/fileadmin/DAM/stats/documents/ writing/MDM_Part3_English_Print.pdf

United Nations. (2014). Making Data Meaningful Part 4: How to improve statistical literacy: A guide for statistical organizations. In United Nations (Vol. 5). http://www.hfrp.org/publications-resources/ browse-our-publications/making-data-meaningful

Wardle, C., Derakhshan, H. (2017). Information disorder: Toward an interdisciplinary framework for research and policy making. Council of Europe 27.

\section{About the authors}

Jaqueline Vasconcelos Braga

jaqvasconcelos@gmail.com

Universidade de Brasília, Brasil

Tiago Barros Pontes e Silva

tiagobarros@unb.br

Universidade de Brasília, Brasil

Submission date: $21 / 4 / 2021$

Approvement date: 2/11/2021 